\title{
A Comprehensive Study on the Baffling Global Regulatory Expectations: Combination Products (Drug-Device)
}

\author{
Dhiraj Behl* and Harikesh Kalonia \\ Amity Institute of Pharmacy, Amity University, Noida, Uttar Pradesh, India \\ Corresponding author email: dhiraj1987@gmail.com
}

\begin{abstract}
Combination products and drug delivery devices aid in patient compliance and a movement toward point-of-care at home. The objective of study is present an overview regulatory requirement of combination of Drug-device and highlights on the legal basis of the current regulation in the regulated countries like United stated, Europe etc. regarding drugs, biologics, and medical devices in general and will discuss the regulatory processes involved in getting a combination product into approval processes. A total of 95 review and research paper including regulatory guidelines, regulations as well as directives on combination of Drug-device by international regulatory agencies were reviewed. The pharmaceutical authorizations process generally comprises two main stages, a clinical trial request, and a marketing authorizations application to the regulatory authority. Each country is responsible for implementation of rules and regulations and laying down the guidelines for regulating drug promotion in its own regulatory authority. Once a lead molecule has been found, a drug should be conducted in a non-clinical way to ensure effectiveness and safety. After a request is made to the competent authority of the country concerned, clinical trials were then being conducted. The trial phases are performed in accordance with the protocol. Approval to market the medication is reviewed by the competent authority and approved if the drug is met to support consistency, safety, and efficacy issues. In conclusion there is a need to development of common quality of rules, regulation and directives. Guidelines for regarding drug product marketing and regulatory authority
\end{abstract}

KEY WORDS: DRUG- DEVICE, COMBINATION PRODUCTS, APPROVAL PROCESS.

\section{INTRODUCTION}

Different countries currently need to comply with different regulatory standards in order to approve new medicines. A one regulatory method is virtually a problematic task in many countries for Marketing Authorizations Application (MAA). Awareness of the MAA regulatory requirements of each country must therefore be accessible. Every nation takes its individual regulatory supplies to satisfy in this specific country for the approval of a new medicinal product. An only regulatory attitude in various countries of the approval of new medicine remains problematic towards apply. Sensitization of regulatory matters of various

Biosc Biotech Res Comm P-ISSN: 0974-6455 E-ISSN: 2321-4007

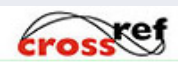

Identifiers and Pagination

Year: 2021 Vol: 14 No (6) Special Issue

Pages: $472-480$

This is an open access article under Creative

DOI: $h t t p: / / d x . d o i . o r g / 10.21786 / b b r c / 14.7 .98$
Commons License Attribn 4.0 Intl (CC-BY). countries therefore essential (Chakraborty and Yadav, 2013; Ellul et al., 2016; Hampton et al., 2017; Sawant et al., 2018; Purnama and Drago, 2019; Vreman et al., 2020).

This article therefore illustrates various countries' regulatory strategies. When developing combination products, the local legal requirements are extremely inconstant and getting more complicated with the integration of new technologies emerging: - USA: FDA has highlighted the requirements and expectation for the development and manufacture of combination products (CP)under $21 \mathrm{CFR}$ Part 4. Additionally, manufacturers must follow the GMP requirements for the medicinal product separately as per 12 CFR 210/211, relevant controls (certain sections of 21 CFR 820 ) for the progress of medical devices also required to be fulfilled (Bright, 1999; Honorio, 2011; Di Mario, 2011; Parvizi and Woods, 2014; FDA, 2016).

- European Union: Medicinal substances used in combination with a medical device, including also when they enable the delivery of drugs. The MDR and therefore the EMA Quality Guideline

\section{Article Information}

Received: $10^{\text {th }}$ Aug 2021

ccepted after revision: $1^{\text {st }}$ Nov 2021 
for Combination Products don't use precisely the same terms for combination products classification. Devices incorporating a medicinal substance as an integral part: The medicinal product is an integral part of the device (MDR Article 1. Devices intended to administer a medicinal product: The medicinal product is administered via a medical device (MDR Article 1(Boulton, 2013; Boumans, 2016).

- CA/AU/JP: drug-device combination products are mentioned within thein the local regulations (AUS/JP: no specific definition of a drug-device (CP)depending on the PMOA (primary mode of action) they are regulated as drug or device.

Application for authorization to achieve clinical trials should have sent to competent authority of a country concerned. In four steps, clinical trials are conducted to ensure safety, effectiveness, and then human optimization of the drug. A request for marketing authorization is then complete authorized by the competent authority, where the drug meets the safety and effectiveness criteria and demonstrates that its benefits exceed its risks.

Figure 1: Drug approval regulatory process

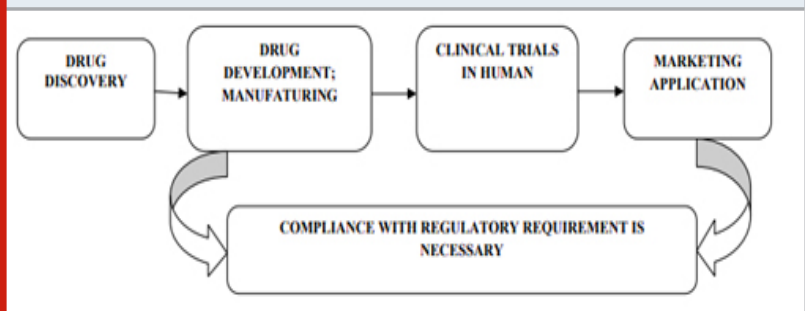

Figure 2: Drug-delivery device (DDD) regulatory pathway - USA

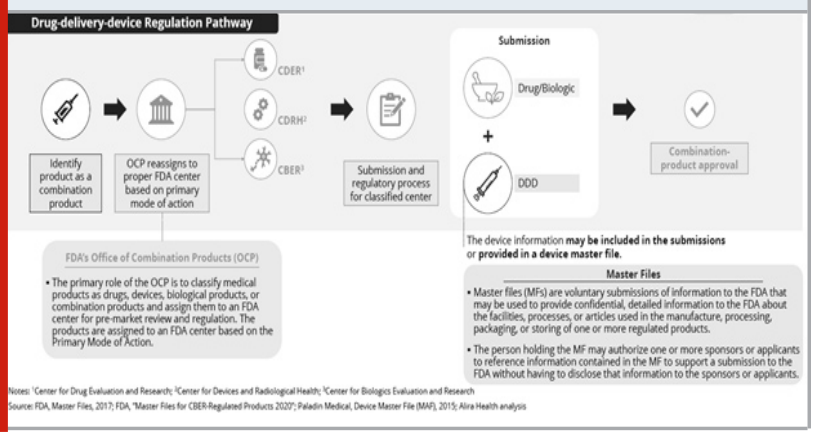

The New Drug Application (NDA) is demand of authorization of marketing of a new drug, which are novel product, give in to the individual governing agencies. Promoter provides preclinical research data and clinical research data for analysis, summary of production tests, of the drug details to get this authorization. Clinical trials different phases as- first is pre-clinical analysis, clinical trial, examining trial, Assenting trial, after marketing trial. Such requests are currently accepted in eCTD format for analysis. NDA's greatest concern is the safety and efficiency of the commodity. The process of approval for FDA starts only after a new drug (IND) application has been submitted.
The United States Pharmacopeia (USP) Drug Law and Regulations is launched in 1820 .

Set drug strength and cleanliness guidelines. Key milestones in United States drug law development include: The two divisions of IND are industrial and academic categories. In three broad ranges, the IND request must contain: (1) Studies in animal medicine and toxicology (2) Information on manufacturing and (3) protocols and clinical researchers Details. The sponsor must wait for 30 when the IND is submitted days before clinical trials are started. FDA has been in the process have a chance to study the protection of the IND to ensure that Themes are not exposed to excessive danger (Braillon, 2010; Guidance, 2011; Basu and Hassenplug, 2012; Komiyama et al., 2016; Hampton, 2017; Sawant et al., 2018; Suzanna et al., 2021).

Figure 3: Trial of New Drug Application

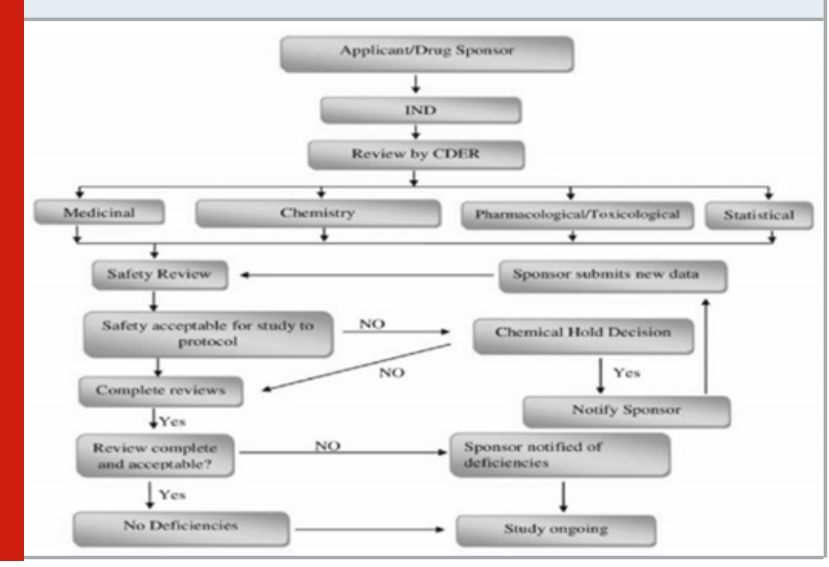

Figure 4: New Drug Application

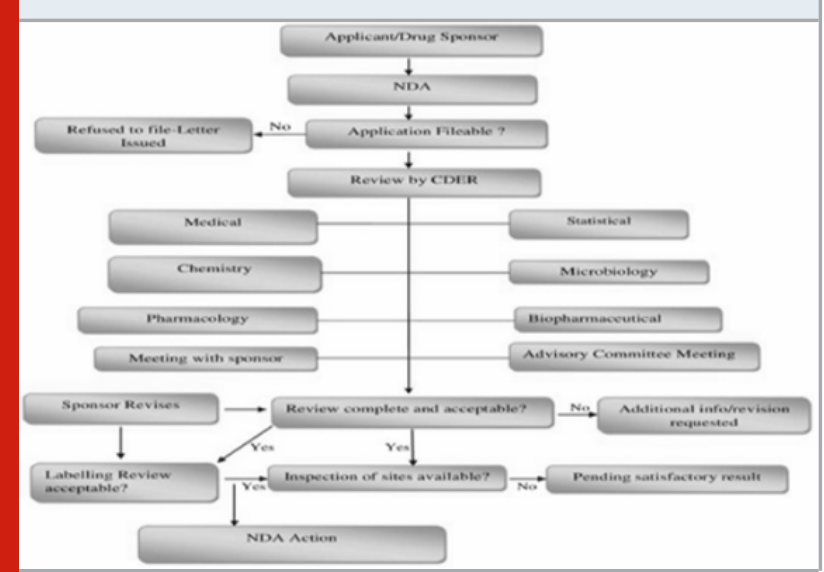

Content and format of IND: The material and IND application format specifications are set out in section of 312 in 21 Code Federal Regulations (CFR). In following order an "Investigative New Drugs Application" must be presented to the promoter (profitable organization)/ detective of plans to perform clinical research.

New Drug Application (NDA): New Drug Request stands submitted towards receive marketing authorization for new drug in United States. The NDA provides details in the IND and the outcomes of safety and efficacy clinical trials. 
In 60 days of the proposal of NDA, the FDA shall begin the review process. NDA format and content 2 copies of request: (A) File copy (B) review copy. Copy of Review: In every folder every technical section is bound separately. Form 356 h Copy of FDA, note of cover copy, Permission letters and Description copy of the request

At least two meetings with the sponsor should be held by the FDA: once at the conclusion of Phase second and earlier the presentation of an NDA. That is pre-NDA meeting. The review terminology will be evaluating the findings of the analysis and decide whether or not the application will be approved (Begg and Berlin, 1988; Kaplan et al., 2004; Campbell, 2013; Kashyap et al., 2013; Komiyama et al., 2015).

ANDA is functional for products with equal associated active ingredients, doses, strength, route of administration, use of the abbreviated New Drug Application ANDA. ANDA and marking is already proved safe and successful as a commodity. These medicines are called generic medicines that can Comply with norms of biology and pharmaceuticals. At an ANDA The Drug Evaluation and Research Center is sent to the Office of Generic medicines for which it is verified and licensed (Kuhlmann et al., 1999; Jefferys, 2001; Bhatt, 2004; Gøtzsche and Jørgensen, 2011; Boulton, 2013; Sorenson and Drummond, 2014; Lepola et al., 2016).

Figure 5: Abbreviated New Drug Application (ANDA)

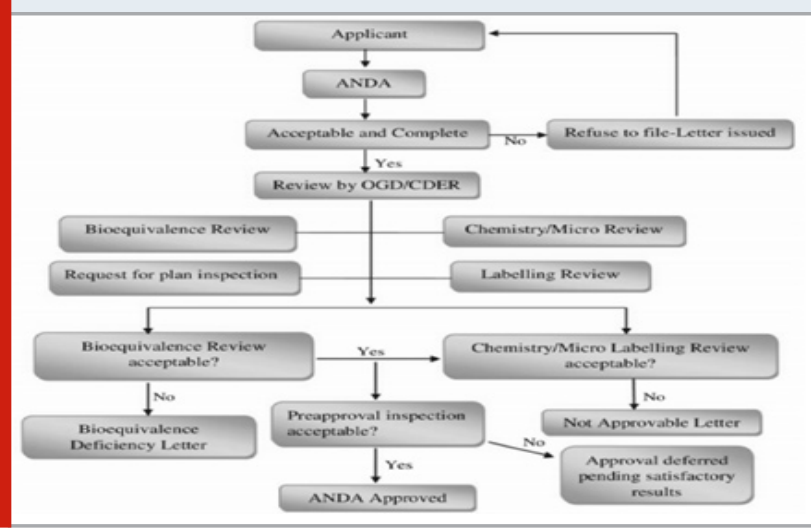

The FDA's "Licensed Drug Products with Therapeutic Equivalence Evaluations" is titled the Orange Book. All approved medicinal products, including branded and generic products. It comprises products which are inspected by the FDA for both safety and efficiency and certified for NDAs or ANDAs. The report also offers clinical equivalency assessments for prescription multi-source drug products containing the same active ingredients (Gupta et al., 2012; Sawant et al., 2018).

Drug Approval Process in Europe: The EMEA was set up in London in 1995 to coordinate with Members States of the European Union (EU) the evaluation and supervision of together veterinary and human medicinal products. It implemented a straightforward process to produce, consult, finalize and enforce the drug guidelines. The process of drug approval is completed in two stages in European countries: Testing clinical. Authorizations to market.

\section{Figure 6: Graphical representation of drug device}
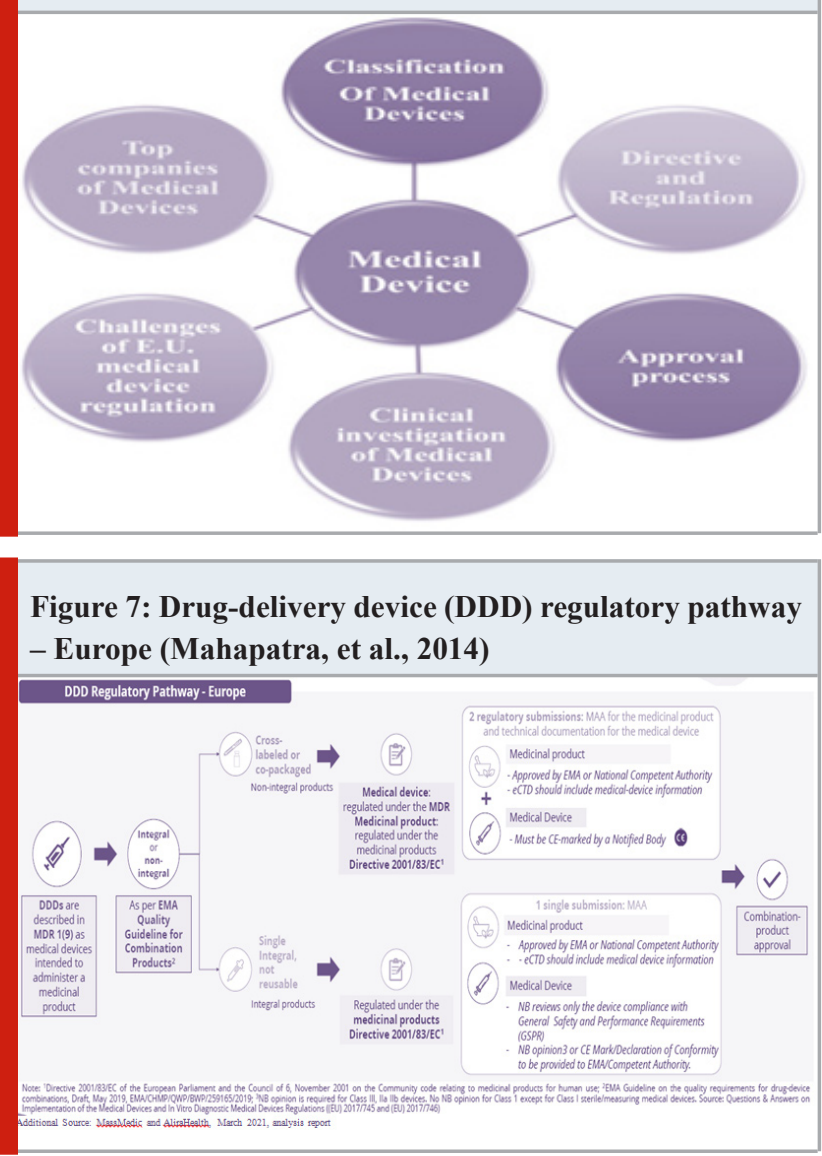

Capable right to government performs clinical trial within European Union is filed a Clinical Trial Application -CTA (EU). This application is evaluated by the competent authority of that Member State. Only after approval are the clinical trials performed. Only after all three stages of clinical trials had completed is a marketing authorization application submitted. The following volumes, entitled The Rules governing therapeutic products in the European Union, have released the European legislation that contains the pharmacological orders.

- Vol.1: Medicines for Human Use Pharmaceutical Legislation

- Vol. 2: Medicine applicants for Human Use Notice

- Vol. 3: Medicinal products scientific rules for human use

- Vol. 4: Good medicine and veterinary manufacturing practice guidelines

- Vol. 5: Medicine for Veterinary Use Pharmaceutical Regulations

- Vol. 6: Notice to veterinary application applicants for medicinal products.

- Vol. 7: Scientific guidelines on veterinary medicinal products

- Vol. 8: Most limits for residues

- Vol. 9: Rules on Pharmacia vigilance for Human and 
Veterinary Medicinal Products

- Vol. 10: Clinical Studies Guidance

In order, to gain market authorization for medical products Europe has various processes and administrative procedures.

In the European Union there are four different ways to get pharmaceutical marketing clearance.

- National Competent Authority (NCA) responsible for:

\section{o National procedure}

o Mutual recognition procedure

o Decentralised procedure

o Repeat use procedure

- $\quad$ European Medicines Agency (EMA) responsible for: o Centralised procedure - European Commission decision

Procedure of Centralized: The centralized process enables applicants to receive an EU-wide marketing authorization. An application for biotech products and new chemical entities is approved in this procedure (NCEs). All biotechnology products are grouped under the heading ' $A$ ' and NCEs under the heading of 'B.' This practice applies to the entire European Union and to a single marketing license. The EMEA team shall check the wholeness and conformity of an application of EU guidelines upon receipt of the Marketing Authorization Approval (MAA). This assessment necessity to be done within ten days of the date of application is submitted. The sponsor pays the corresponding expenses. The submission must then be considered by EMEA for 210 days. They may appoint rapporteurs to evaluate the Medicinal Products for Human Use application and report. CHMP offers its opinion where the request should be accepted or refused; it is forwarded to the European Commission for 90 days for a decision to be reached. The approval period is approximately 300 $(210+90)$ days. Under this product, the EMA application is accepted by all member countries (Zuckerman et al., 2011; Bhave, 2018; Vreman et al., 2020).

\section{Figure 8: Shows Centralized Procedure}

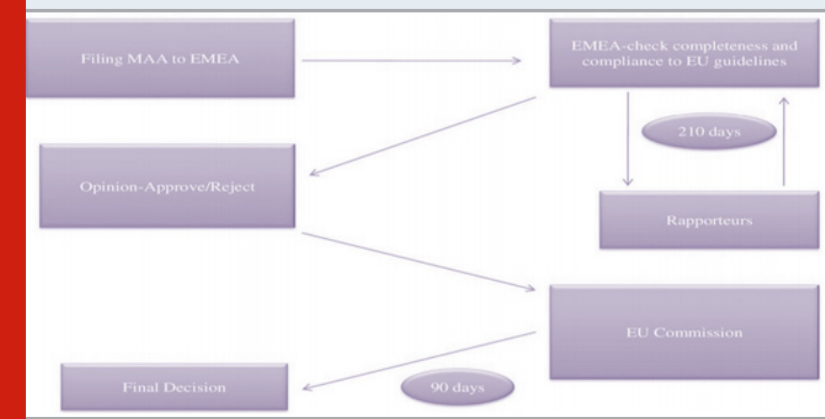

Decentralized Procedure: This means that commodity is simultaneously accepted by a coalition of Member States. It is regarded as a process that is very efficient. In order, to receive marketing permits in various Member States decentralized procedure is followed. The sponsor shall send the request and list of the Member States concerned (CMS) to the national regulatory authority specifying a Member State of reference (RMS). The application must be validated by the RMS and Product Feature Summary (PFSA).

The breeze evaluation report must be drawn up within 210 days, and a copy may be sent to the CMS within 90 days. If a drug is meant to pose a possible serious health risk. CMSs will object and the CHMP intervenes then and decides in 30 days' time. However, in many countries under this scheme a negative decision does also not affect the registration of the following product: Medicine of Orphans, Orphans. All products, specified Aids and cancer medicines, based on biotechnology; Defined antiviral drugs, neurodegenerative disorder specified medicines like diabetes or Auto immune/ dysfunction specified drugs.

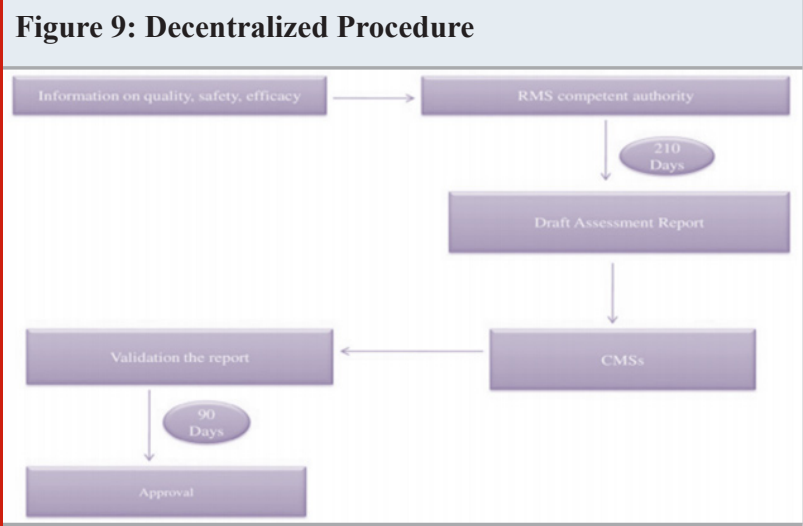

Figure 10: National Procedure

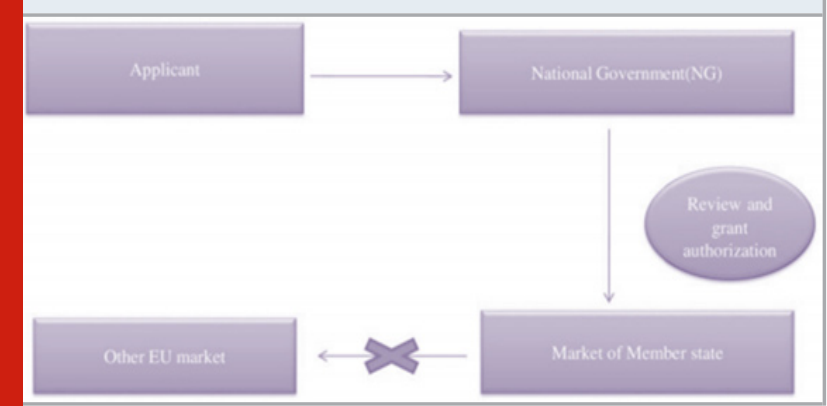

Europe nation has own edits regulatory agency. Even small businesses can pay the fees. It saves on English or regional translation costs. It provides a foundation for mutual recognition Proceedings the registration of biotechnology methods by national procedure cannot be made. The centralized submission via EMA is mandatory. The application is revised and the marketing authorizations issued by sponsor under national rules of national competent authority. The following products are not registered under this scheme, too: The Medicine of Orphan, the Specified Aids and Cancer Medicines, Antiviral Medicaments Specified, Neurodegenerative Drugs Specified, as well as diabetes and Autoimmune Diseases/Dysfunction Specified Medicines. The following may not be included under this Scheme: 
Figure 11: Mutual Recognition Procedure (MRP)

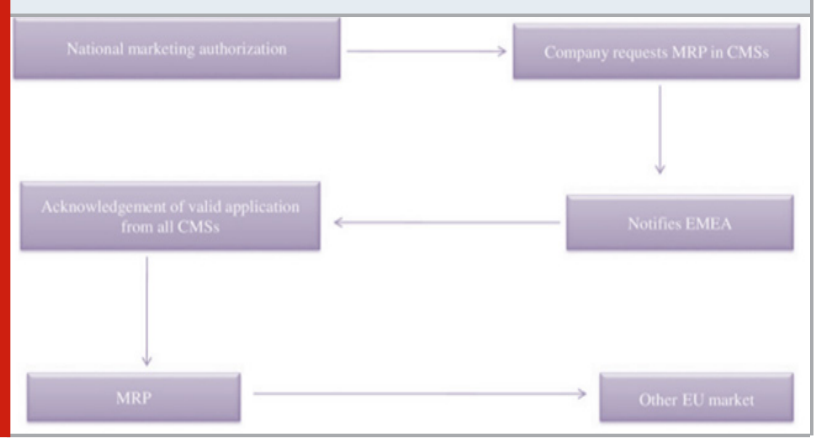

The other country recognizes each other as a product licensed in one country. The application must be submitted for initial registration only once. Another Member State accepts the same application with some regional modifications. Member Countries in the EU Evaluation Report on medicinal product: A copy evaluation report can be sent to the CMSs and any appeals may be made within 90 days by any other Member State and the RMS. A national marketing authorization with the same SPC is issued by each CMS. The following substance cannot be registered in accordance with this scheme: Specified AIDS and Cancer Medicine, quantified antiviral medicines, specified medicines for neurodegenerative disorders, orphan's medical product, All Biotechnology related products. Including diabetes and autoimmune disease drugs specified / Functions of malfunctions (Sorenson and Drummond, 2014; Lepola et al., 2016).

Regulation of combination products in Canada: These Rules refer to the selling and publication of a medical device for sale and the importation for sale by persons supplementary than importation for personal usage of a medical device. The report was released. It has the following structure:

a) Drug/Medical Device Hybrid Products Policy establishes standards to be considered and approved as a combination product for combination drugs and devices. The following:

b) Drug/Medical Device Policy Mix Products - Decisions - shall provide a TPD classification in accordance with the Drug/Medical Device Matching Products Policy with examples of combinations falling beneath the policy and cases where the drug/medicine assertion is not valid.

Prior in 2006 sponsor of combinations of drug-device products to meet two rules. A combination product's medicinal component was subject to the Food and Drug Regulations and the device component was subject to Medical Device Regulations. The BGTD subsequently determined that the associated risks of a combination product of adequately handled under one set of rules and that Drug/Medical Device Combination Products Policy was released, as a result of an appreciation of the regulatory burden that it provided for sponsors and discouragement of marketing combination products in Canada. However, the Directorates reserve the right to reclassify goods where continued classification results in an unauthorized or excessive application of fees or other regulatory requirements. The Directorates do not use this policy retrospectively on any products already listed as drugs or devices. This policy does not extend to medication/medical device combinations where the drug component and device component can be used separately (e.g., products sold together in procedure packages and trays). The drug part of such mixture is covered by the Food and Drug Regulations and the device component is covered by the Medical device Regulations (Ravinder and Suresh, 2011; Resnic, 2012; Jungbäck and Motitschke, 2014; Hampton et al., 2017)

In its regulatory and development framework, the organization of a combined product as a drug or medical device is the most critical step and must be taken early, either to promote the selling of the product or to facilitate an inquiry into the product in Canada. The first step in deciding combination product classification is to consult the Combination Products - Decisions on the Drug and Medical Device Policy. The combination products of the following kinds are listed in compliance with Drug/Medical Device Combination Products Policy by the Therapeutic Products Classification Committee (TPCC). This list contains products that are not combination products, but which are not easily determined by the classification of either medication or unit.

Figure 12: Classification of a drug-medical device combination

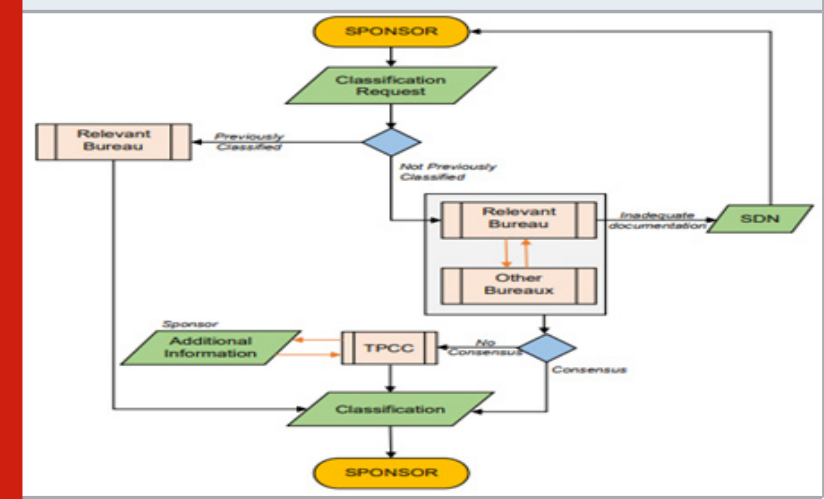

A. Medication labelled combination items

- Patches for transdermal drug delivery

- $\quad$ Prefilled syringes

- Implants with the main purpose of releasing a medication

- Wound dressings, the main object of which is to supply medication

- Medicinal items with the primary objective of dental impregnations pay a medicine

- $\quad$ Packaging solutions for red blood cells

- Media of comparison

- Options for peritoneal dialysis

- Swabs in spirit

B. Combination items known as equipment

- Drug covered equipment such as catheters, pacemaker, or shunt sensors

- Medication systems impregnated

- Wound dressings with antimicrobial agent surgery 
barriers

- Wound dressings with the main objective of acting as an obstacle Pathologists

- Anticoagulant blood bags or preservative solutions

- Antibiotic bone cement - new vacuum fillers for the bone, for example collagen.

- Morphogenic protein bone matrix

- Sodium hyaluronate nasal solution

- Injectable collagen

- Urea breath examination (accessory to device)

- Photodynamic cell processing ex vivo unit

C. drug and product combinations not covered by this Policy that must conform both to the Food and Drug Regulations and Medical Devices Regulations

- $\quad$ Kits (e.g., medication and system epidural trays; drug and equipment first aid kits)

- Products not covered by any number of regulations:

- Minimum tissue manipulation

If the products are not specified, the classification is obtained, a key move. The following page in Figure shows the flow chart

Sponsors or suppliers may send a written classification application to the applicable review center of a combination product which are not previously classified, or they may submit a TPD, BGTD or MDD submission for the purpose of classifying a product before submitting a submission or application as necessary for a classification request. Otherwise, sponsors should file a Review Centre/Bureau/ Office on their basis for a submission/application. Own grade own.

In order to govern the export, manufacture, distribution and sales of medicines and cosmetic products, the Indian Parliament proclaimed the Drug and Cosmetic Act in 1940 and the Regulation in 1945. Central Drugs Standard Control Organization (CDSCO) was founded and its head office in DCGI. In 1988, Annex Y to the Drug and Cosmetics Rules 1945 was introduced by the Indian government. Schedule $\mathrm{Y}$ sets out the clinical trial protocols and standards that have been updated in 2005 to match the globally approved protocol. When a business in India wishes to manufacture/ import the new medication, it must also submit the data set out in Annex Y of the Drugs and Cosmetic Law 1940 and Rules 1945 to ask the licensee for permission to submit in Form 44.

$122 \mathrm{~A}$ is the Drug and Cosmetics Act states new products approved for used many years than other countries can be waived in case of new trials. For those medicinal products that are discovered in India, all phases of clinical trials must be protected in Section 2.4(a) of Schedule Y of Drugs and Cosmetic Act in 1940 and Rules in 1945. In Article of the Drugs and Cosmetics Act of 1940 of Schedule Y and Rules in 1945, it is said that the applicants should apply data available from other countries and may require them to repeat the studies or permit the licensing authority to conduct clinical trials in Phase III for drug substances discovered from countries other than India. Demonstration of safety and effectiveness of a drug product for human use before the drug product is authorized by the Central Drugs Standard Control Organization for importation or manufacture by the applicant for the drug product (CDSCO). The drug and cosmetics legislation 1940, as well as the regulations $1945,122 \mathrm{~A}, 122 \mathrm{~B}$ and $122 \mathrm{D}$ provide details necessary for the approval of the import/manufacture application for new drug. In India the need for local clinical trials depends on drug status in other jurisdictions. In other countries, phase III trials are usually necessary if the medication is already approved. Phase I trials in India are not permitted unless data from other countries are available. DCGI's permission to perform Phase 1 studies in India is given when the drug is relevant for a health issue in India, such as malaria or tuberculosis (Jungbäck and Motitschke, 2014; Hampton et al., 2017).

In accordance with BABE guidelines, studies in the biodisposability and bioequivalence (BABE) field should be carried out. Extensive information on the marketing status of the medication is essential in other countries other than safety and efficacy information. It is also essential to send information concerning consignments, samples and testing protocols, product monographs and labels. Clinical trial approval in India normally takes three months. Info of clinical trials and subjects involved in trials can reported on the Clinical Trials Registry of India (CTRI). The drugs and cosmetics laws of 1945 shall be followed: The following rules. The amendments to the Drugs and Cosmetics Law include defining Stage I- IV studies and creating specific researchers and sponsors obligations. In 2006, the clinical studies were split into two more groups. Clinical trials in one category (category A) may be performed on other market with qualified and mature regulatory structures while the rest of them fall into a different category (category B). Other than A. Quick trackers in India are qualified and will probably be accepted within a period of eight weeks in clinical trials Group A (approved in the United States, UK, Switzerland, Australia, Canada,Japan, and the EU). The Category B clinical trials will be further examined within 16 to 18 weeks and approved (MacLean, 2003; McKenna, 2009; Roberts et al., 2011; Kramer et al., 2012a; Kramer et al., 2012b; Mahapatra et al., 2014; Stafford et al., 2014; Norman and Van, 2016).

\section{Stages of approval}

1. Submit a request to evaluate safety and effectiveness for clinical trials

2. New approval of medicines requirements

3. Improvements in consistency, protection, and effectiveness documents for post-approval ofa biological products

4. Preparation of quality information for the new drug approval

In most of the countries, the format of CTD was announced. Also, for technical registration requirements for human pharmaceutical goods CDSCO has adopted CTD format.

Combination of products regulation in Australia: Australia combine goods are not regulated as a single product therefor are regulated allowing to its key function or meaning. The Administration of Therapeutic Goods 
(TGA) is part of Australia's Health and Ageing Department, liable for therapeutic regulation. Goods include medicinal drugs, medical equipment, blood products and products of blood. Therapeutic Goods Act in 1989 is administered by the TGA. This regulation provides a basis of the risk management approach to enable a therapeutic product which is consistently secure, efficient and of high quality to the Australian Community in a timely manner. The Therapeutic Goods Act in 1989 regulates medicinal products, as amended by the Therapeutic Goods Amendment Bill in 2002, as well as by the Regulations on Therapeutic Goods (2002). Combination of products are known medicines or devices according to their PMOA and are regulated accordingly (Kramer et al., 2012; Norman and Van, 2016; Kondo et al., 2018).

\section{Figure 13: Drug approval process in India}

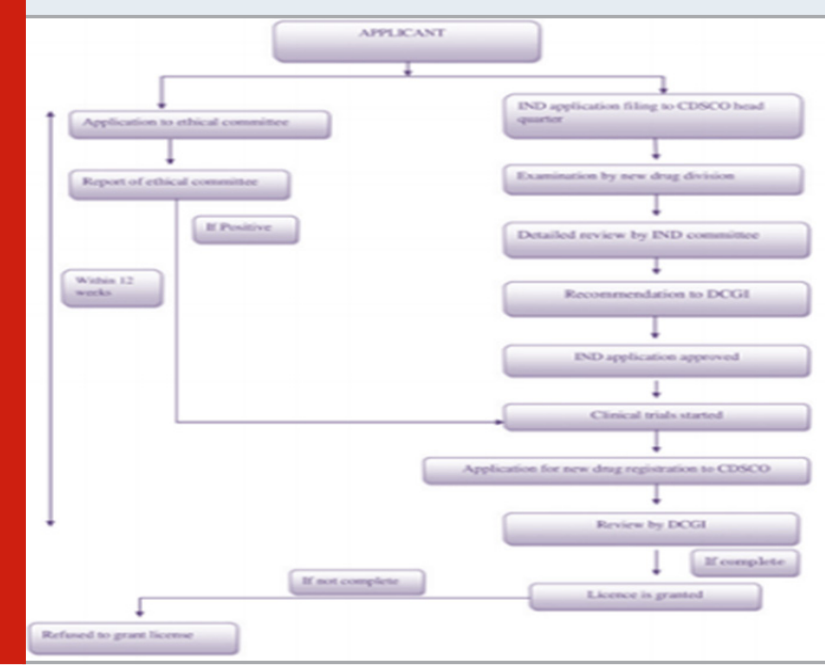

In China, State Food and Drug and organization are regulatory body for approval of medicinal products (SFDA). These products, which are regulated in the China under the SFDA, are regulated under Medical Devices Department, which regulates medical devices. This drug/device combination is referred to in China as a medicinal product. The SFDA Department of Drug Registration is liable for controlling medicinal products then certain products that is medicinal products, are delivered by different means than their own, so they are subject to medical device regulations, such as catheters and medicinal elucidation stents. Approval of medicinal element in country of source required for registration of these products in China before being presented in China. The knowledge of medical equipment works together with the drug department in the assessment of a drug containing product. For final approval of these drugs, the technical assessment center of the system department works with a drug review specialist (Lee et al., 2008; Parvizi and Woods, 2014; Van Norman, 2016; Purnama and Drago, 2019).

Brazil is one of the ten world's top medical device markets. In 2006 Brazil was recognized as the 12th chief medical device of world in 2007, rendering to Epsicom, at US\$ 2,585 million. In 2011 it is projected that the medical device market will cross $\$ 3$ billion. The import is limited; however, the market increases demand for higher technology medical equipment. With local and multinational companies Brazil has a well-developed medical devices industry that provides approximately 70 percent of the market. Much of the enterprises are located in south-east Brazil, São Paulo and Paraná. In conjunction with Argentina, Paraguay and Uruguay, Brazil is a part of the South Common Market (Lachman, 1976; Zuckerman, 2011; McCulloch, 2012; Boumans et al., 2016; Hampton et al., 2017).

Portuguese Agency of National Health Surveillance (ANVISA) is the capable organization for medical devices in Brazil. Brazil is the national health supervisory body. Before leaving Brazil, ANVISA must register all medical equipment, diagnostical kits, immune biologic, and sanitation products. Law No. 6360 of 1976, Decree 74.094/97 regulates medical equipment. The key resolution for medical devices is Resolution RDC-185 of 22 October 2001. This resolution specifies the documentation needed for a product registration and includes a procedure for registration. The conditions for the registration of in vitro diagnostic devices are set out in Resolution RDC No.206 of November 2006 (Basu and Hassenplug, 2012; Bhave, 2018; Agrawal et al., 2019).

Class I, Class II, Class III, and Class IV are classified between Medical devices. The minimum risk is Class I, and the maximum Risk is Class IV. According to the GHTF proposals, Brazil Class I is European Class I, Brazil Class II is the European Class IIa, Brazil Class III is the European Class IIb, and Brazil Class IV is European Class III. Annex II of RDC 185, 22 October 2001 contains the rules of classification. With the exceptions of Rules 8 and 13[42], the Brazilian rules are the same as European rules. Brazil has introduced the nomenclature system for universal medical devices (UMDNS). In-vitro diagnostic devices are subdivided together in six separate classes and, according to "Familias de Produtos Diagnósticos de uso In-Vitro" on the ANVISA website, are describing a total of 87 family devices.

\section{CONCLUSION}

In different countries, the combination products (drugdevice) or any other classification, which only applies to such products, are not limited. In the other countries. These products are governed in the majority of countries allowing to chief purpose or intent of combined product, just as in case of a combination of drug devices if the main part of the product is physical, the primary role of the medical device is controlled by the division of medicine and the primary role of the drug is chemical. The concept of combination products in different countries is presented to explain the legislation for such product. In several nations, around no clear regulatory method to such goods. Differences in existing legislation and frameworks in regulatory bodies require manufacturers to be ready to meet various regulatory routes in different regions. For sponsors and manufacturers to accept these goods, there are therefore different obstacles. 


\section{ACKNOWLEDGEMENTS}

The authors are most grateful to Dr. Janine Jamieson for her kind help and sharing insights for Combination products as a part of research as well as want to thank Dr. Mannu Babber for his technical assistance.

\section{REFERENCES}

Agrawal, V., Shrivastava, T.P., Adusumilli, P.K., Vivekanandan, K., Thota, P. and Bhushan, S.,(2019). Pivotal role of Pharmacovigilance Programme of India in containment of antimicrobial resistance in India. Perspectives in clinical research, 10(3), p.140.

Altenstetter, C., (2003). EU and member state medical devices regulation. International journal of technology assessment in health care, 19(1), pp.228-248.

Annex, I.I., (1993). Council Directive 93/42/EEC of 14 June 1993 concerning medical devices.

Basu, S. and Hassenplug, J.C., (2012). Patient access to medical devices: a comparison of US and European review processes. The New England journal of medicine, 367(6), pp.485-488.

Begg, C.B. and Berlin, J.A., (1988). Publication bias: a problem in interpreting medical data. Journal of the Royal Statistical Society: Series A(Statistics in Society), 151(3), pp.419-445.

Bhave, A., (2018). Indian regulatory update: JanuaryDecember 2017. Perspectives in clinical research, 9(1).

Bhatt, A., (2004). Clinical trials in India: Pangs of globalization. Indian Journal of Pharmacology, 36(4), p.207.

Boulton, A.J., (2013). Registration and regulation of medical devices used in diabetes in Europe: need for radical reform. The Lancet Diabetes \& Endocrinology, 1(4), pp.270-272.

Boumans R. (2016) The Future of Eudamed-Better, Bigger, Riskier. EmergoGroup blog, February 1, 2016. Available at: http://www.emergogroup. com/blog/2016/02/ future-eudamed-better-biggerriskier. Accessed June 3,pp. 24-31

Braillon, A., (2010). Medical devices and the approval processes: United States vs France. Archives of internal medicine, 170(22), pp.2040-2041.

Bright, J., (1999). European medical device regulatory law and product liability. Journal of hospital infection, 43, pp.S169-S173.

Campbell, B., (2013). Regulation and safe adoption of new medical devices and procedures. British medical bulletin, 107(1).

Chakraborty, K. and Yadav, K., (2013). Drug approval process in US, Europe and India and its regulatory requirements: A Review.

Cohen, D. and Billingsley, M., (2011). Europeans are left to their own devices. Bmj, 342 .

Curfman, G.D. and Redberg, R.F., (2011). Medical devices - balancing regulation and innovation. The New England journal of medicine, 365(11), pp.975-977.
Downing, N.S., Aminawung, J.A., Shah, N.D., Braunstein, J.B., Krumholz, H.M. and Ross, J.S., (2012). Regulatory review of novel therapeutics - comparison of three regulatory agencies. New England Journal of Medicine, 366(24), pp.2284-2293.

Di Mario, C., James, S., Dudek, D., Sabate, M. and Degertekin, M., (2011). Commentary: The risk of overregulation. Bmj, 342.

Ellul, I., Grech, V. and Attard-Montalto, S., (2016). Can Registration Procedures of Pharmaceuticals Inadvertently Contribute to Off-Label Prescribing in Children?. Therapeutic innovation \& regulatory science, 50(6), pp.808-816.

Fargen, K.M., Frei, D., Fiorella, D., McDougall, C.G., Myers, P.M., Hirsch, J.A. and Mocco, J., (2013). The FDA approval process for medical devices: an inherently flawed system or a valuable pathway for innovation?. Journal of neurointerventional surgery, 5(4), pp.269-275.

Food and Drug Administration, (2014). Developing products for rare diseases \& conditions. 201308-15]. http://www. fda. gov/Forlndustry/ DevelopingProductsforRareDiseasesConditions/default. htm.

FDA, U., (2016). Recalls, market withdrawals, \& safety alerts. Background and definitions. Available [online] from: http://www. fda. gov/Safety/Recalls/ucm 165546. htm.[Accessed: 23 Dec. 2016].

Gupta, N.V., Reddy, C.M., Reddy, K.P., Kulkarni, R.A. and Shivakumar, H.G., (2012). Process of approval of new drug in India with emphasis on clinical trials. Marketing, 6, p.8.

Gøtzsche, P.C. and Jørgensen, A.W., (2011). Opening up data at the European Medicines Agency. Bmj, 342.

Guidance, C.D.E.R., (2011). A review for OCRA US RAC Study.

Hampton, D., Green, J.A., Robboy, M. and Eydelman, M., (2017). Food and Drug Administration Efforts to Mitigate Contact Lens Discomfort. Eye \& contact lens, 43(1), pp.2-4.

Honorio, S., (2011). Phases of drug development; Good practices in clinical research.

http://www.cdsco.nic.in/writereaddata/Guidance_for New_Drug_Approval-23.07.2011.pdf

http://citeseerx.ist.psu.edu/viewdoc/download?doi=10.1. $1.375 .519 \& \mathrm{rep}=\mathrm{rep} 1 \&$ type $=\mathrm{pdf}$

Jefferys, D.B., (2001). The regulation of medical devices and the role of the Medical Devices Agency. British journal of clinical pharmacology, 52(3), pp.229-235.

Jungbäck, C. and Motitschke, A., (2014). Official testing of immunological veterinary medicinal products. Bundesgesundheitsblatt, Gesundheitsforschung, Gesundheitsschutz, 57(10), pp.1193-1197.

Lachman, L., Lieberman, H.A. and Kanig, J.L., (1976). The theory and practice of industrial pharmacy (pp. 210-212). Philadelphia: Lea \&Febiger.

Kashyap, U.N., Gupta, V. and Raghunandan, H.V., (2013). Comparison of drug approval process in United States \& 
Europe. Journal of pharmaceutical sciences and research, 5(6), p.131.

Kaplan, A.V., Baim, D.S., Smith, J.J., Feigal, D.A., Simons, M., Jefferys, D., Fogarty, T.J., Kuntz, R.E. and Leon, M.B., (2004). Medical device development: from prototype to regulatory approval. Circulation, 109(25), pp.3068-3072.

Kondo, E., Torii, M., Oba, I. and Okamoto, M., (2018). The pharmaceuticals and medical devices Agency's approach to facilitate risk communication and its challenges. Yakugakuzasshi: Journal of the Pharmaceutical Society of Japan, 138(3), pp.307-314.

Kuhlmann, J., (1999). Alternative strategies in drug development: clinical pharmacological aspects. International journal of clinical pharmacology and therapeutics, 37(12), pp.575-583.

Komiyama, O., Kotonari, A., Kokan, A. and Kubota, K., (2015). Good pharmacovigilance planning in Japan: Proposals from the "task force for good pharmacovigilance planning in Japan" of Japanese Society for Pharmacoepidemiology (JSPE). Japanese Journal of Pharmacoepidemiology, 20(2), pp.73-83.

Kramer, D.B., Xu, S. and Kesselheim, A.S.,( 2012a). Regulation of medical devices in the United States and European Union.

Kramer, D.B., Xu, S. and Kesselheim, A.S.,(2012b). How does medical device regulation perform in the United States and the European union? A systematic review.

Lee, K., Bacchetti, P. and Sim, I., (2008). Publication of clinical trials supporting successful new drug applications: a literature analysis. PLoS medicine, 5(9), p.e191.

Lepola, P., Needham, A., Mendum, J., Sallabank, P., Neubauer, D. and de Wildt, S., (2016). Informed consent for paediatric clinical trials in Europe. Archives of disease in childhood, 101(11), pp.1017-1025.

Mahapatra K, A., Sameeraja, N.H. and Murthy, P.N., (2014). Drug approval process-in United States of America, European Union and India: a review. Applied Clinical Research, Clinical Trials and Regulatory Affairs, 1(1), pp.13-22.

MacLean, C.H., Morton, S.C., Ofman, J.J., Roth, E.A. and Shekelle, P.G., (2003). How useful are unpublished data from the Food and Drug Administration in meta-analysis?. Journal of clinical epidemiology, 56(1), pp.44-51.

McKenna, C., (2009). Understanding the medical device directive changes. Biomedical instrumentation \& technology, 43(4), pp.319-320.

McCulloch, P., (2012). The EU's system for regulating medical devices.

Norman GA Van (2016) Drugs and Devices. JACC Basic to Transl Sci 1: 399-412

Nair, Y.M. and Martin, D.K., (2004). Concerns about ethical review of health research in India. Indian journal of medical ethics, 1(4), pp.119-120.

Parvizi, N. and Woods, K., (2014). Regulation of medicines and medical devices: contrasts and similarities. Clinical medicine, 14(1), p.6.

Pharmaceutical Administration and Regulations in Japan, Japan Pharmaceutical Manufacturers Association, March 2014 (JPMA, 2014) - http://www.jpma.or.jp/about/issue/ gratis/index2.html (Japanese) - http://www.jpma.or.jp/ english/parj/whole.html (English)

Purnama, A. and Drago, D., (2019). Fundamentals of the European devices regulatory framework. CPD with Regultory Rapport.

Ravinder, R.B. and Suresh, N., (2011). Regulatory stages for New Drug approvals.

Resnic, F.S., (2012). Postmarketing surveillance of medical devices--filling in the gaps. The New England journal of medicine, 366(10), p.875.

Roberts, S.A., Allen, J.D. and Sigal, E.V., (2011). Despite criticism of the FDA review process, new cancer drugs reach patients sooner in the United States than in Europe. Health affairs, 30(7), pp.1375-1381.

Sawant, A.M., Mali, D.P. and Bhagwat, D.A., (2018). Regulatory Requirements and Drug Approval Process in India, Europe and US. Pharmaceut Reg Affairs, 7(210), p.2.

Sorenson, C. and Drummond, M.,(2014). Improving medical device regulation: the United States and Europe in perspective. The Milbank Quarterly, 92(1), pp.114-150.

Stafford, N., (2014). Only 3 in 20 new drugs approved in Germany in 2011 were an improvement, report says.

Suzanna, G.P., Dongre, P., Nimmagadda, A. and Polshettiwar, S., (2021). Leveraging consumer's knowledge, attitude, and practices in the management of Drug Counterfeiting. Annals of the Romanian Society for Cell Biology, 25(6), pp.17297-17312.

Van Norman, G.A., (2016). Drugs and devices: comparison of European and US approval processes. JACC: Basic to Translational Science, 1(5), pp.399-412.

Vreman, R.A., Bloem, L.T., Van Oirschot, S., Hoekman, J., Van Der Elst, M.E., Leufkens, H.G., Klungel, O.H., Goettsch, W.G. and Mantel-Teeuwisse, A.K., (2020). The role of regulator-imposed post-approval studies in health technology assessments for conditionally approved drugs. International Journal of Health Policy and Management. Zuckerman, D.M., Brown, P. and Nissen, S.E., (2011). Medical device recalls and the FDA approval process. Archives of internal medicine, 171(11), pp.1006-1011. 